\title{
Habilidades cognitivo-linguísticas e segmentação lexical em Braille ${ }^{1}$
}

\author{
Clarissa de Arruda Nicolaiewsky² \\ Jane Correa \\ Universidade Federal do Rio de Janeiro, Rio de Janeiro-RJ, Brasil
}

\begin{abstract}
Resumo: O presente estudo examinou a relação entre habilidades cognitivas e linguísticas e segmentação lexical na produção textual em braille de 21 alunos dos três primeiros anos do ensino fundamental de instituição especializada em deficiência visual. A habilidade de demarcar os limites das palavras no texto é desenvolvida ao longo do processo de aquisição da língua escrita, sendo fundamental para a compreensão textual. Foi investigada a ocorrência de hipossegmentações (junção de duas ou mais palavras) e hipersegmentações (espaço indevido inserido em uma palavra) na produção escrita de histórias. Houve predominância de hipossegmentações. Os participantes que apresentaram maior número de hipossegmentações em sua escrita obtiveram desempenho mais baixo nas tarefas referentes à habilidade verbal, memória de trabalho, consciência morfológica e leitura. Em oposição, aqueles que realizaram menos transgressões obtiveram melhor desempenho nessas tarefas. A elaboração de práticas pedagógicas que enfoquem habilidades cognitivas e linguísticas facilitaria a aquisição da língua escrita em braille.
\end{abstract}

Palavras-chave: processos cognitivos, linguagem escrita, deficiente visual, desenvolvimento cognitivo.

\section{Cognitive-linguistic abilities and word segmentation in Braille}

\begin{abstract}
This study investigated the influence of cognitive and linguistic skills on unconventional written word segmentation in Braille of 21 students attending the first three years of the elementary school in an institution specialized in visual impairment. The ability to establish word boundaries in a text is developed during the long process of written language acquisition and plays an important role in text comprehension. The occurrence of hyposegmentation (junction of two or more words) and hypersegmentation (space incorrectly inserted in a word) was investigated in the written production of stories. Hyposegmentation was significantly more frequent than hypersegmentation. The students who presented a larger number of hyposegmentation performed worse in tasks of verbal ability, working memory, morphological awareness and reading, whereas those with fewer hyposegmentation occurrences performed better. The development of pedagogical activities focusing on cognitive and linguist abilities can favor the acquisition of Braille written language acquisition.
\end{abstract}

Keywords: cognitive processes, written language, visually disabled, cognitive development.

\section{Habilidades cognitivo lingüísticas y segmentación léxica en Braille}

Resumen: Este estudio examinó la relación entre las habilidades cognitivas y lingüísticas y la segmentación léxica en la producción de textos en Braille de 21 alumnos de los tres primeros años de educación primaria de una institución especializada en discapacidad visual. La habilidad de demarcar los límites de las palabras en el texto se desarrolla durante todo el proceso de adquisición de la lengua escrita, teniendo papel muy importante para la comprensión textual. Fue investigada la ocurrencia de hiposegmentaciones (unión de dos o más palabras) y hipersegmentaciones (espacio indebido insertado en una palabra) en la producción escrita de historias. Hubo predominio de hiposegmentaciones. Los participantes que presentaron mayor número de hiposegmentaciones en su escritura, obtuvieron desempeño más bajo en las tareas referentes a la habilidad verbal, memoria de trabajo, conciencia morfológica y lectura. Por otro lado, aquellos que realizaron un número menor de transgresiones, obtuvieron mejor desempeño en las tareas. La elaboración de prácticas pedagógicas que enfocadas en habilidades cognitivas y lingüísticas facilitaría el aprendizaje de la escritura en Braille.

Palabras clave: procesos cognitivos, lenguaje escrito, discapacidad visual, desarrollo cognitivo.

A descoberta da relação entre a fala e a escrita tem significativa importância no início do processo de aquisição

1 Este artigo é baseado na Dissertação "Segmentação lexical na produção textual infantil em braille", apresentada ao Programa de Pós-graduação em Psicologia da Universidade Federal do Rio de Janeiro em março de 2008, pela primeira autora, bolsista CAPES, sob orientação da segunda autora. Agradecemos a CAPES, ao CNPq e a FAPERJ pelo apoio que tornou possível a produção desta pesquisa, bem como à instituição de ensino onde ela foi realizada, pela confiança e acolhida. Agradecemos também aos aprendizes cegos pelo muito que nos ensinaram sobre a forma como desenvolvem suas habilidades. Este texto foi revisado seguindo Acordo Ortográfico da Língua Portuguesa (1990), em vigor a partir de $1^{\circ}$ de janeiro de 2009.

2 Endereço para correspodência:

Clarissa de Arruda Nicolaiewsky. Rua Dias da Rocha, 71/602. CEP 22.051-020. Rio de Janeiro-RJ, Brasil. E-mail: clarissanicolaiewsky@ yahoo.com.br da língua escrita. A partir da compreensão do princípio alfabético, ou seja, do entendimento de que a escrita representa os sons da fala, a criança passa a relacionar os elementos sonoros presentes nas palavras e letras, até alcançar a escrita alfabética (Correa, 2001; Ferreiro, 2001). Inicialmente o aprendiz acredita que a correspondência entre sons e letras seja biunívoca, isto é, que cada som é representado por somente uma letra e que cada letra representa apenas um som (Lemle, 2003). Com o progresso em seu aprendizado e sua crescente experiência com a leitura e a escrita, o aprendiz compreende que existem também relações múltiplas entre sons e letras. Há letras que representam mais de um fonema, como é o caso do grafema $c$, que representa o fonema $/ \mathrm{s} /$ em cenoura e o $/ \mathrm{k} /$ em casa, assim como um fonema como $\mathrm{o} / \mathrm{s} /$ que pode ser representado por diferentes letras (seta, 
cebola, assunto, excesso, açúcar, auxílio). O aprendiz toma, então, consciência de que na língua portuguesa as relações grafofonêmicas nem sempre são biunívocas, e que diversos aspectos deverão ser levados em conta para se escrever ortograficamente.

Assim, o domínio da escrita ortográfica demanda conhecimentos que vão além do fonológico. Tendo em vista que a comunicação escrita se dá predominantemente por meio de textos, outras habilidades são ainda necessárias para o domínio pleno da língua escrita, como, por exemplo, a organização das palavras em frases e das frases em parágrafos. Embora a delimitação das palavras na escrita por espaços em branco pareça algo simples e natural para o adulto alfabetizado, tal formatação não é intuitiva e depende das convenções da escrita e de seu aprendizado. A forma como separamos as palavras no texto escrito e dispomos as frases em parágrafos foi disseminada a partir da Idade Média, com o intuito de facilitar a leitura silenciosa e a cópia (Günther, 1997).

\section{Segmentação lexical na escrita}

No caso da separação das palavras na escrita, essa marcação é realizada por um sinal de pontuação ou por um espaço em branco (Tolchinsky \& Cintas, 2001). O desenvolvimento da habilidade de demarcação dos limites das palavras na escrita de acordo com as normas ortográficas se dá de forma gradual. São dois os tipos de segmentação lexical não convencional encontrados na produção do aprendiz: a hipersegmentação e a hipossegmentação (Ferreiro, Pontecorvo, Moreira, \& Hidalgo, 1996). A hipersegmentação refere-se a uma separação indevida das palavras (por exemplo, de pois; em bora) e a hipossegmentação a uma junção de palavras onde deveria haver uma separação (por exemplo, agarota; sedeitou; denovo).

Tendo em vista que a compreensão de um texto por qualquer leitor será, em princípio, influenciada pela clareza e organização proporcionadas pelo escritor, o domínio das formas gráficas terá, portanto, grande relevância para a produção textual escrita. A segmentação das palavras nas frases contribui para a atribuição e distinção de significados no texto escrito (Ferreiro e cols., 1996). Uma pequena mudança na segmentação escolhida pelo aprendiz pode, por exemplo, resultar em diferentes significados atribuídos a uma mesma frase: "O menino pego uma pá.", "O menino pegoumapa." ou "O menino pego u mapa.". Dessa forma, dependendo da segmentação realizada pelo aprendiz, o objeto direto pode ser uma pá ou um mapa.

A escolha não convencional do espaço em branco na escrita geralmente não se dá ao acaso, sendo fruto de hipóteses construtivas por parte do aprendiz (Ferreiro e cols., 1996). A habilidade de segmentar convencionalmente as palavras está relacionada, entre outros aspectos, aos conhecimentos morfológicos da criança, tendo sido observada maior facilidade em segmentar substantivos e adjetivos de forma convencional em comparação com pronomes, preposições e conjunções (Gombert, 1992; Sandbank, 2001; Tolchinsky \& Cintas, 2001). Além disso, há evidências de que o contexto sintático também influencie na escolha de demarcação dos limites no texto, tendo sido encontradas diferenças de acordo com a localização e a função das palavras nas frases, havendo número significativamente maior de hipossegmentações nos elementos próximos aos verbos - pronomes reflexivos e advérbios - em relação aos determinantes, elementos próximos aos substantivos (Tolchinsky, 2006). Desta forma, o desenvolvimento da consciência morfossintática poderia contribuir para o domínio da habilidade de segmentar o texto de forma convencional.

Correa e Dockrell (2007) observaram influência significativa da consciência morfológica na habilidade de delimitação das palavras no texto em português brasileiro em crianças de desenvolvimento típico. As crianças que realizaram menor número de segmentações não convencionais em seus textos obtiveram desempenho superior na tarefa de consciência morfológica, enquanto aquelas que apresentaram mais transgressões foram as mesmas que obtiveram desempenho mais baixo nessa tarefa. Assim, a sensibilidade das crianças à morfologia teve papel fundamental no desenvolvimento da habilidade de segmentação convencional das palavras, tanto ao se tornarem capazes de separar preposições, pronomes e determinantes dos substantivos e verbos próximos, quanto ao de manter palavras intactas (Correa \& Dockrell, 2007).

Ao examinarem o papel da memória de trabalho no desenvolvimento da segmentação lexical, Correa e Dockrell (2007) não encontraram correlação significativa. Tal resultado indica que a ocorrência de segmentações não convencionais não estaria relacionada com limitações no processamento cognitivo relativas ao uso da memória de trabalho.

Correa e Dockrell (2007) encontraram ainda evidências da importância da habilidade verbal e do nível de leitura para a segmentação convencional das palavras na escrita. As crianças que realizaram menor número de segmentações não convencionais em seus textos obtiveram desempenho superior nas tarefas relacionadas às habilidades verbais e à leitura, enquanto aquelas que realizaram número relativamente maior de transgressões apresentaram desempenho inferior nas mesmas tarefas.

Tendo em vista que o conhecimento das relações grafofonêmicas é um dos pilares do processo de aquisição da língua escrita, servindo como base para a construção de outros conhecimentos e habilidades, é possível que um melhor domínio das relações grafofonêmicas, fundamental na leitura, facilite o desenvolvimento da segmentação lexical. Essa habilidade de decodificação na leitura poderia, ainda, contribuir para uma melhor competência em lidar com determinados elementos, como preposições, artigos e pronomes, possibilitando a segmentação convencional dos mesmos na escrita (Correa \& Dockrell, 2007).

Foi observada, ainda, relação significativa entre escolaridade e ocorrência de segmentações não convencionais. A maioria das crianças do primeiro e segundo anos realizou 
maior número de segmentações não convencionais em sua escrita, enquanto a maioria dos alunos do terceiro ano realizou menor número de transgressões em sua produção textual, o que aponta para a contribuição dos avanços em linguagem e domínio da língua escrita para a compreensão das características relativas ao processo de demarcação dos limites das palavras no texto (Correa \& Dockrell, 2007).

Tais resultados evidenciam que o desenvolvimento da segmentação lexical na língua portuguesa acontece de forma gradual, estando relacionado ao desenvolvimento da habilidade verbal, da consciência morfológica e do nível de leitura dos aprendizes. Não é possível afirmar, no entanto, se o processo de aquisição da segmentação lexical ocorreria da mesma forma caso o sistema de representação escrita da língua fosse outro, como é o caso do sistema braille, um sistema tátil de representação da língua, que possui algumas particularidades, como, por exemplo, a impossibilidade de realizar a leitura global das palavras, como acontece regularmente na leitura convencional (Pring, 1994). Além disso, menos oportunidade de contato com a leitura poderia ser outro fator a influenciar o desenvolvimento da segmentação convencional das palavras, já que as oportunidades de inserção dos aprendizes em práticas sociais de leitura e escrita em braille fora do ambiente escolar são ainda pouco frequentes. A presença do sistema braille na sociedade brasileira restringe-se, por exemplo, a painéis de elevadores, remédios e alguns produtos da indústria alimentícia. Tendo em vista a importância da leitura e da escrita na sociedade contemporânea e a obrigatoriedade de se assegurar o direito de indivíduos cegos a uma escolarização de qualidade (Ministério da Educação, 2006), a melhor compreensão acerca dos fatores envolvidos no processo de desenvolvimento da segmentação lexical em braille teria papel relevante para a elaboração de práticas pedagógicas relacionadas à aquisição da língua escrita em braille.

\section{A escrita pelo sistema braille}

A inclusão escolar e social de indivíduos cegos tem o sistema braille como uma de suas ferramentas mais relevantes. Segundo Belarmino (2007), o surgimento desse sistema significou um salto qualitativo nas relações estabelecidas entre o indivíduo cego e o meio. O braille permite ao aprendiz cego o contato com diversos saberes, possibilitando maior inserção cultural. Ademais, esse competente sistema, além de favorecer a autonomia no acesso à informação, pode também tornar a localização no ambiente mais acessível, facilitando, assim, a autonomia do indivíduo no seu ir e vir (Stone, 1995), um direito básico que deve ser garantido a todos.

É de fundamental importância, portanto, melhor compreensão acerca da aquisição da língua escrita em braille. Cada letra e sinal gráfico em braille são formados a partir de diferentes combinações de seis pontos em relevo, dispostos em duas colunas de três pontos, compondo a matriz denominada cela Braille. Esses seis pontos configuram, portanto, um retângulo, que mede apenas seis milímetros de altura por dois de largura. Tais características conferem maior complexidade a esse sistema em relação ao sistema impresso, já que, em razão da similaridade entre as letras, o aprendizado da língua escrita em braille demanda um desenvolvimento refinado da coordenação motora fina e da orientação espacial. As dificuldades no domínio do sistema braille acarretam, com frequência, a produção de erros não intencionais que resultam na transformação de uma letra em outra (Gosche, Schwartz, \& Wells-Jensen, 2007; Nicolaiewsky, 2008).

A padronização na localização dos pontos e celas Braille, fundamental para a compreensão leitora, é garantida pelos instrumentos utilizados na escrita. Tal padronização impede, no entanto, a correção de erros relativos à segmentação lexical no momento de revisão do próprio texto por não ser possível inserir nem retirar espaços. Por esse motivo, é de fundamental importância que se realize a segmentação convencional das palavras no momento da primeira escrita do texto. É possível que tais especificidades do sistema braille resultem em diferenças no desenvolvimento da segmentação lexical por aprendizes cegos em relação ao processo percorrido pelos visonormais. Tendo em vista as relações entre as segmentações lexicais não convencionais e as habilidades e conhecimentos utilizados pelas crianças na construção da escrita, bem como a relevância do domínio da língua escrita em braille como instrumento de inclusão social, o presente artigo tem como objetivo examinar a relação entre as habilidades cognitivas e linguísticas e a ocorrência de segmentações não convencionais na produção textual em braille.

\section{Método}

\section{Participantes}

Participaram desta pesquisa 21 alunos cegos inscritos no primeiro, segundo e terceiro anos do ensino fundamental de uma instituição de ensino especializada em deficiência visual, sendo sete participantes do primeiro ano, seis, do segundo e oito, do terceiro. É importante clarificar a razão pela qual os participantes da pesquisa são denominados cegos. A deficiência visual pode ser classificada em dois níveis: cegueira e visão reduzida. Em termos pedagógicos, a visão do indivíduo considerado cego não lhe permite aprender a ler e a escrever formas gráficas e, portanto, ele deve utilizar recursos didáticos táteis, como o sistema braille. Já na visão reduzida ou baixa visão, é possível aprender a ler e a escrever graficamente, embora sejam necessários recursos especiais como ampliação da letra e/ou lentes de aumento. Dessa forma, o método pedagógico utilizado na educação de crianças com baixa visão assemelha-se bastante ao de crianças visonormais. Nesse sentido, como a pesquisa tem como foco o sistema braille, os participantes selecionados são todos crianças e jovens considerados pedagogicamente cegos. Tendo em vista o objetivo da pesquisa, participaram apenas aqueles que já tinham um conhecimento mínimo da língua escrita em braille, sendo capazes de produzir frases. 
Os responsáveis pelos alunos foram contatados para explicação dos objetivos e procedimentos da pesquisa, sendo a participação dos aprendizes realizada após a assinatura do Termo de Consentimento Livre e Esclarecido, elaborado de acordo com o Comitê de Ética em Pesquisa do Hospital Universitário Clementino Fraga Filho da Universidade Federal do Rio de Janeiro. É importante esclarecer que as entrevistas foram realizadas no período do contraturno e em momentos, definidos pelas professoras, que não interfeririam no processo de aprendizagem dos alunos.

A idade média dos participantes do primeiro ano foi de 10 anos e 11 meses. A idade média do segundo ano foi de 11 anos e 11 meses e a do terceiro ano foi de 12 anos e 6 meses. $\mathrm{Na}$ instituição, alunos novos acima de 7 anos são matriculados no primeiro ano, a não ser que tenham o conhecimento necessário para serem inseridos em outros anos. Por esse motivo, foi frequente encontrar alunos com idades avançadas nessas séries iniciais.

\section{Instrumentos}

De forma a obter a avaliação da habilidade verbal dos participantes, foram utilizados os seguintes subtestes da escala verbal do Wechsler Intelligence Scale for Children (WISC-III), padronizado para uma amostra brasileira (Figueiredo, 2001): Informação, Semelhança, Aritmética, Vocabulário e Compreensão. O teste Informação tem como objetivo investigar o conhecimento escolar e cultural dos participantes, enquanto o de Semelhança solicita a explicitação das semelhanças entre pares de objetos e de conceitos. O teste Aritmética investiga o conhecimento matemático, o de Vocabulário examina a habilidade de descrição do significado de diversas palavras e o de Compreensão objetiva avaliar a resolução de problemas cotidianos e a compreensão de regras e conceitos sociais. Em virtude das restrições visuais dos participantes, os subtestes utilizados foram adaptados de acordo com pesquisa realizada por Nascimento e FloresMendoza (2007).

O subteste Dígitos da escala verbal do WISC-III foi empregado para avaliação da memória de trabalho, não tendo sido necessária a adaptação do material (Nascimento \& Flores-Mendoza, 2007). O subteste Dígitos é composto por uma série de sequências numéricas, que vão gradualmente se tornando mais extensas, apresentadas oralmente, que devem ser repetidas literalmente nos itens de Ordem Direta e, em ordem inversa, nos itens de Ordem Inversa.

O nível de leitura dos participantes foi investigado pelo teste de leitura de palavras do Teste de Desempenho Escolar (TDE). Trata-se de um teste padronizado (Stein, 1994), que visa avaliar o conhecimento acerca das representações grafofonêmicas por meio da leitura em voz alta das palavras apresentadas. De forma a adaptar sua aplicação aos participantes, as 70 palavras que compõem o teste foram escritas em braille em fitas de rotuladora e coladas em folhas de papel. As fitas de rotuladora foram utilizadas por permitirem uma maior durabilidade dos pontos. Caso as palavras tivessem sido escritas diretamente na folha, à medida que os participantes as lessem, os pontos tornar-se-iam menos nítidos, dificultando a leitura dos demais.

Tendo como objetivo analisar o conhecimento morfológico dos participantes, foi utilizada uma tarefa de analogia morfossintática composta por itens (Correa \& Dockrell, 2007). Cada item era formado por dois pares de palavras, sendo que o segundo par deveria ser completo oralmente pelo aprendiz. Dessa forma, era esperado que o estudante compreendesse a relação gramatical entre o primeiro par de itens na tarefa e que conseguisse aplicá-la intencionalmente ao segundo par. Por exemplo, um dos itens apresentados era composto do par de palavras corredor/correr, seguido da palavra jogador, que deveria ser completo com a palavra que estava faltando. Assim, dever-se-ia utilizar o radical da palavra jogador para gerar uma palavra que pertencesse à mesma classe gramatical de correr, ou seja, deveria gerar um verbo a partir de um substantivo, para que a mesma relação gramatical fosse mantida no segundo par de palavras. Desse modo, a tarefa avaliava a habilidade de refletir sobre o processo de formação de palavras e de identificar a transformação morfológica presente no primeiro par de palavras e aplicar essa mesma transformação ao segundo par.

\section{Procedimento}

A pesquisa foi aprovada pelo Comitê de Ética em Pesquisa do Hospital Universitário Clementino Fraga Filho da Universidade Federal do Rio de Janeiro. Todas as entrevistas foram realizadas individualmente, tendo sido necessárias três a quatro entrevistas por participante, com duração de aproximadamente 40 minutos cada. A fim de investigar a possível ocorrência de segmentações lexicais não convencionais na escrita, foi solicitada a cada aprendiz a produção de uma história inventada. Segundo Ferreiro e cols. (1996), em pesquisas com crianças visonormais, são frequentemente observadas dificuldades na análise dos dados referentes às segmentações de palavras. Há situações em que é difícil definir se o espaço em branco colocado pelas crianças refere-se a um espaço entre palavras ou entre letras, principalmente quando a escrita utilizada não é a cursiva. Na presente pesquisa, como o espaço entre letras ou palavras é estabelecido pelo próprio instrumental utilizado, não há dúvidas relativas à segmentação. No entanto, mais propensão a erros de pontos, com a consequente transformação de uma letra em outra, acarreta maior dificuldade na compreensão do que foi escrito. Com o intuito de sanar essas dúvidas, foi solicitado a cada aprendiz ler sua produção em voz alta, leitura esta gravada em fita cassete.

\section{Resultados}

Foi investigada a ocorrência de segmentações lexicais não convencionais na escrita espontânea de histórias dos aprendizes, calculando sua frequência de ocorrência para comparação do desempenho escrito nos diferentes anos 
escolares. A proporção de segmentações não convencionais foi calculada levando-se em consideração o número de palavras escritas nas produções textuais dos participantes, uma vez que na comparação dos valores absolutos de tais segmentações poder-se-ia incorrer em uma avaliação inadequada. Por exemplo, na ocorrência de mesmo número de hipossegmentações na escrita de dois participantes, um deles tendo escrito um texto de apenas 15 palavras, enquanto o outro, um texto de 85 palavras, deve-se considerar que o segundo aprendiz tem mais domínio das convenções da escrita, em relação à segmentação das palavras no texto, do que o primeiro aluno.

De forma a comparar o desempenho entre os anos escolares, foi calculada a proporção média das segmentações não convencionais. No que diz respeito à proporção média de hipossegmentações em relação às palavras escritas, observou-se a ocorrência de $14 \%$ de hipossegmentações no primeiro ano, $2 \%$ no segundo e $1 \%$ no terceiro ano. É possível verificar a influência significativa da escolaridade para o domínio da segmentação lexical na escrita (Teste da Mediana Chi-Square $=6,20, d f=2, p=0,04)$. Os aprendizes no primeiro ano cometem, do ponto de vista estatístico, significativamente mais hipossegmentações na escrita do que aqueles dos segundo e terceiro anos $\left(M d \mathrm{n}_{1}=0,07 ; M d \mathrm{n}_{2}=0,01 ; M d \mathrm{n}_{3}=0,00\right)$.

Quanto às hipersegmentações, foi encontrada a proporção média por palavras escritas de $1 \%$ no primeiro ano, $0 \%$ no segundo e $0,2 \%$ no terceiro ano. A frequência de ocorrência de hipersegmentações ocorridas nos textos dos aprendizes cegos é baixa em relação ao número de palavras escritas. Constata-se, portanto, um número mais expressivo de hipossegmentações em comparação às hipersegmentações, o que também acontece na escrita de crianças visonormais (Carraher, 1985; Correa \& Dockrell, 2007; Ferreiro e cols., 1996; Tolchinsky \& Cintas, 2001).

A frequência de segmentações não convencionais, tanto de hipossegmentações quanto de hipersegmentações, nos textos dos aprendizes cegos foi, de forma geral, semelhante àquela encontrada nos textos de crianças visonormais brasileiras (Correa \& Dockrell, 2007), exceto pela frequência de ocorrência de hipossegmentações na escrita dos aprendizes cegos no primeiro ano escolar, que foi superior à frequência de hipossegmentação encontrada para as crianças visonormais em processo de alfabetização por Correa e Dockrell (2007).

De forma a buscar compreender quais das habilidades cognitivas e linguísticas poderiam estar relacionadas à habilidade de segmentar convencionalmente as palavras na produção textual em braille, foi realizada uma análise de Cluster apenas para os casos de hipossegmentação. Não foi realizada uma análise referente às hipersegmentações em razão de sua baixa ocorrência nas produções textuais analisadas. A análise dividiu os participantes em dois grupos, de acordo com a ocorrência de hipossegmentações. O primeiro grupo, composto por dez jovens, foi formado por aqueles que realizaram maior número de hipossegmentações em sua escrita.
O segundo grupo, composto por onze jovens, foi formado por aqueles que realizaram menor número de hipossegmentações em seus textos. A Tabela 1 apresenta o perfil dos dois grupos, em termos das habilidades cognitivas e linguísticas examinadas.

Tabela 1

Médias de ocorrência de hipossegmentação e das habilidades cognitivas e linguisticas

\begin{tabular}{lcccc}
\hline & \multicolumn{2}{c}{ Grupo 1 } & \multicolumn{2}{c}{ Grupo 2 } \\
\cline { 2 - 5 } & \multicolumn{2}{c}{$(n=\mathbf{1 0})$} & \multicolumn{2}{c}{$(n=\mathbf{1 1})$} \\
\cline { 2 - 5 } & $M$ & $D P$ & $M$ & $D P$ \\
\hline Hipossegmentação & 0,12 & 0,2 & 0,01 & 0,01 \\
Habilidade Verbal & 72,7 & 13,35 & 103,73 & 15,84 \\
Memória de Trabalho & 7,5 & 2,07 & 10,64 & 3,11 \\
Consciência Morfossintática & 0,52 & 0,16 & 0,7 & 0,12 \\
Leitura & 0,68 & 0,23 & 0,9 & 0,08 \\
\hline
\end{tabular}

O exame das médias apresentadas na Tabela 1 mostra que os participantes inseridos no Grupo 2 têm desempenho significativamente melhor do que os do Grupo 1 nas atividades envolvendo a habilidade verbal $\left(M d \mathrm{n}_{1}=71,50\right.$; $M d \mathrm{n}_{2}=97,00$, Mann-Whitney $\left.\mathrm{U}=4,5 n_{1}=10, n_{2}=11, p<0,01\right)$, memória de trabalho $\left(M d \mathrm{n}_{1}=7,00 ; M d \mathrm{n}_{2}=10,00\right.$, Mann-Whitney $\left.\mathrm{U}=17,500, n_{1}=10, n_{2}=11, p=0,008\right)$, consciência morfossintática $\left(M d \mathrm{n}_{1}=0,55 ; M d \mathrm{n}_{2}=0,70\right.$, Mann-Whitney $\mathrm{U}=16,000$, $\left.n_{1}=10, n_{2}=11, p=0,006\right)$ e leitura $\left(M d n_{1}=0,76 ; M d n_{2}=0,90\right.$, Mann-Whitney $\left.\mathrm{U}=16,000, n_{1}=10, n_{2}=11, p=0,006\right)$.

Em suma, constata-se a existência de relação inversamente proporcional entre a ocorrência de hipossegmentações na escrita de aprendizes cegos e o desenvolvimento de habilidades linguísticas e cognitivas. Os alunos que apresentaram maior número de hipossegmentações em sua escrita foram aqueles que obtiveram desempenho mais baixo nas tarefas referentes à habilidade verbal, leitura, memória de trabalho e consciência morfossintática. Em oposição, aqueles que realizaram número relativamente menor de hipossegmentações em seus textos obtiveram melhor desempenho nas tarefas que avaliaram as habilidades cognitivas e linguísticas acima mencionadas.

Em estudo com crianças visonormais brasileiras (Correa \& Dockrell, 2007), em que foi também analisada a relação entre a ocorrência de hipossegmentações e diferentes habilidades cognitivas e linguísticas, foi observado que as crianças que realizavam maior número de hipossegmentações na escrita eram aquelas que tiveram desempenho mais baixo em habilidade verbal, em nível de leitura e em consciência morfológica. No entanto, não foi encontrada relação significativa entre a ocorrência de hipossegmentações e a memória de trabalho, ao contrário da presente pesquisa. É possível hipotetizar, portanto, no caso do sistema braille, por ser um sistema 
tátil, que haja demanda maior de processamento cognitivo durante a leitura do que acontece regularmente no sistema de escrita convencional.

A análise realizada apontou também para a influência da escolaridade no domínio da segmentação lexical na escrita, como ilustra a Tabela 2.

\section{Tabela 2}

Distribuição dos participantes antes nos dois grupos da análise de Cluster

\begin{tabular}{lcc}
\hline & Grupo 1 & Grupo 2 \\
\cline { 2 - 3 } & $(n=10)$ & $(n=11)$ \\
\hline $1^{\circ}$ ano & 5 & 2 \\
$2^{\circ}$ ano & 3 & 3 \\
$3^{\circ}$ ano & 2 & 6 \\
\hline
\end{tabular}

A maioria das crianças do primeiro ano estava inserida no grupo referente à maior frequência de hipossegmentações, as crianças do segundo ano estavam distribuídas de forma homogênea e a maioria das crianças do terceiro ano estava inserida no grupo com menor número de hipossegmentações. Tal resultado destaca o caráter gradual do desenvolvimento da habilidade de segmentação lexical no decorrer do processo de aquisição da língua escrita em braille.

\section{Discussão}

A presente pesquisa buscou compreender a relação entre a segmentação lexical na produção textual de aprendizes cegos e sua relação com diversas habilidades cognitivas e linguísticas. Em virtude da escassez de pesquisas brasileiras que retratem a aquisição da língua escrita em braille, esta investigação deve contribuir para a melhor compreensão do tema e impulsionar a elaboração de novas pesquisas que busquem examinar questões relativas ao aprendizado da leitura e da escrita em braille.

Os resultados da presente pesquisa apontam para a importância das habilidades cognitivas e linguísticas para o domínio da escrita ortográfica em braille. Foi observada influência da habilidade verbal, da consciência morfológica, do nível de leitura e da memória de trabalho no desenvolvimento da capacidade de demarcar os limites entre as palavras no texto. Assim, à medida que o aprendiz desenvolve tais habilidades, ele reconstrói suas hipóteses acerca da língua escrita, adquirindo melhor domínio da leitura e da escrita. Tais resultados evidenciam ainda a similaridade entre os fatores relacionados ao processo de aquisição da língua escrita por crianças visonormais e cegas, com exceção da influência da memória de trabalho, que parece ter papel mais significativo no desenvolvimento da segmentação lexical em braille, possivelmente em razão de um maior processamento cognitivo necessário no uso desse sistema de representação escrita. Foi observado, ainda, quando comparada a frequência de segmentações não lexicais na escrita dos participantes com a de crianças visonormais brasileiras (Correa \& Dockrell, 2007), um número superior de hipossegmentações na escrita das crianças cegas do primeiro ano. Pode-se supor que tal fato seja decorrente tanto a uma menor exposição da criança cega a textos em braille quanto à possibilidade de que a percepção dos espaços em braille não seja tão nítida quanto o é para pessoas visonormais, que obtêm uma percepção mais global das palavras e de suas demarcações. No entanto, tendo em vista o número reduzido da amostra, não é possível generalizar esses resultados para todas as crianças cegas que cursam o primeiro ano e nem afirmar que características peculiares desse sistema representacional da língua são a causa da maior dificuldade inicial em segmentar convencionalmente os textos.

O desenvolvimento de habilidades como a consciência morfológica exerce influência relevante no aprendizado da língua escrita e sua promoção deve ser facilitada. Além disso, avanços na linguagem e na aquisição da escrita também contribuem para a compreensão do conceito de palavra e para sua disposição convencional no texto. Desta forma, a promoção de experiências com a língua e de práticas educativas específicas que visem o desenvolvimento da habilidade verbal são fundamentais para a facilitação do domínio da leitura e da escrita.

Cabe destacar que o desenvolvimento da língua escrita inclui tanto a compreensão das propriedades da escrita alfabética e ortográfica quanto o desenvolvimento de habilidades de uso do sistema de escrita em práticas sociais que envolvem o emprego direto ou indireto da língua escrita (Morais, 2006; Soares, 2004). A aquisição da língua escrita deve ser facilitada, então, por atividades pedagógicas diferenciadas, que contemplem essas duas facetas da língua escrita - o domínio do sistema e seu uso contextualizado -, visto que esses são processos interdependentes (Soares, 2004; Rego, 2006). Assim, práticas pedagógicas que visem o desenvolvimento de habilidades fonológicas (Souza \& Bandini, 2007) e morfossintáticas são necessárias para que se compreendam o princípio alfabético e as normas ortográficas da nossa língua. São indispensáveis atividades que focalizem habilidades linguístico-cognitivas e que permitam a reflexão acerca dos aspectos comunicativos e funcionais da língua escrita. É essencial que se desenvolva nos alunos cegos uma atitude crítica durante a produção textual, sensibilizando-os para a importância da escrita como ato comunicativo.

É fundamental, portanto, o desenvolvimento das habilidades cognitivas e linguísticas envolvidas no processo de aquisição da língua escrita, uma vez que elas exercem papel significativo no domínio da leitura e da escrita. É pelo domínio da linguagem escrita que crianças e jovens sentir-se-ão incluídos e participantes de nossa sociedade letrada.

\section{Considerações finais}

O desenvolvimento de pesquisas que objetivem a melhor compreensão dos processos cognitivos envolvidos no 
aprendizado dos diferentes conteúdos escolares por deficientes visuais é fundamental para sua inclusão escolar. É imprescindível que o conhecimento científico produzido seja disponibilizado para os profissionais das instituições escolares. A promoção de um ensino de qualidade, para todos os alunos, só se efetivará com a elaboração de práticas pedagógicas que contemplem as necessidades de cada um e garantam o seu desenvolvimento integral (Dall'acqua, 2007). A utilização de recursos pedagógicos acessíveis também é um ponto-chave na educação de alunos com deficiência visual, que devem ser empregados não apenas com o intuito de facilitar o acesso ao conhecimento, mas, especialmente, para proporcionar atividades conjuntas, favorecendo a interação e a troca de experiências entre todos os alunos (Laplane \& Batista, 2008).

Em pesquisa específica acerca do desenvolvimento da escrita ortográfica em crianças deficientes visuais, Arter e Mason (1994) pontuaram a importância do aprendizado da ortografia por meio de atividades que visem a reflexão acerca da língua escrita. Adicionalmente, grande relevância é atribuída ao domínio ortográfico pelos próprios jovens cegos (Argyropoulos \& Martos, 2006), tanto para a sua inserção no ambiente escolar quanto para facilitar a comunicação escrita. Segundo Argyropoulos e Martos (2006), os jovens apontam ainda o domínio da ortografia como uma das qualificações mais básicas para o ingresso no mercado de trabalho. Assim, é imperativa uma atenção cuidadosa à elaboração de intervenções pedagógicas que objetivem a aquisição e domínio da língua escrita em braille de forma reflexiva.

De acordo com Morais (2003), tendo sido constatado que os erros cometidos pelos aprendizes refletem um nível de conhecimento menos elaborado acerca das convenções de nossa língua, é fundamental, em primeiro lugar, levar o aprendiz a elaborar de forma consciente seus conhecimentos, sendo para isso necessário que as situações de ensinoaprendizagem permitam ao aluno duvidar de suas hipóteses e refletir sobre elas. Esse tipo de atitude demanda, no entanto, uma mudança de paradigma quanto à maneira como o erro é visto no ambiente escolar. Partindo do pressuposto de que os erros são, na realidade, hipóteses elaboradas pelos aprendizes que revelam seus conhecimentos sobre a língua escrita, será possível deixar de simplesmente evitá-los, mas, ao contrário, aceitá-los, propondo reflexões e discussões acerca deles.

Tendo em vista as dificuldades já anteriormente descritas em relação ao domínio da leitura e da escrita em braille e a frequência de erros decorrentes dessas dificuldades, transformar a relação que o aluno cego estabelece com seus próprios erros torna-se imperativo para seu desenvolvimento. Estabelecer, no ambiente escolar, um espaço acolhedor, onde as dúvidas e os erros possam surgir e ser encarados com naturalidade é um primeiro passo para um aprendizado efetivo (Nicolaiewsky \& Correa, 2008).

Morais (2003) sugere situações de ensino-aprendizagem coletivas nas quais se estimule a reflexão a respeito do sistema de escrita. Ao utilizar estratégias que facilitem a interação da turma e promovam a construção de conceitos pelos alunos, o professor será capaz de entender melhor as dificuldades e as possibilidades de cada educando e, assim, facilitar, de forma mais efetiva, o processo de aprendizagem de cada um (Mantoan, 2006).

Considerando a importância do sistema braille para a inclusão social dos indivíduos cegos, pesquisas que enfoquem o seu aprendizado são de extrema relevância para o desenvolvimento de práticas pedagógicas que facilitem o processo de aquisição da língua escrita por deficientes visuais.

\section{Referências}

Argyropoulos, V., \& Martos, A. (2006). Braille literacy skills: An analysis of the concept of spelling. Journal of Visual Impairment \& Blindness, 100, 676-686.

Arter, C., \& Mason, H. (1994). Spelling for the visually impaired child. British Journal of Visual Impairment, 12, 18-21.

Belarmino, J. (2007). Braille e semiótica: Um diálogo relevante. Recuperado em 15 setembro 2007, de http:// www.bocc.ubi.pt

Carraher, T. N. (1985). Explorações sobre o desenvolvimento da competência em ortografia em português. Psicologia: Teoria e Pesquisa, 1, 269-285.

Correa, J. (2001). A aquisição do sistema de escrita por crianças. In J. Correa, A. Spinillo, \& S. Leitão (Orgs.), Desenvolvimento da linguagem: Escrita e textualidade (pp. 19-70). Rio de Janeiro: NAU.

Correa, J., \& Dockrell, J. (2007). Unconventional word segmentation in Brazilian children's early text production. Reading \& Writing, 20, 815-831.

Dall'Acqua, M. J. C. (2007). Atuação de professores do ensino itinerante face à inclusão de crianças com baixa visão na educação infantil. Paideia (Ribeirão Preto), 17, 115-122.

Ferreiro, E., Pontecorvo, C., Moreira, N. R., \& Hidalgo, I. G. (1996). Chapeuzinho vermelho aprende a escrever: Estudos psicolinguísticos comparativos em três línguas. São Paulo: Ática.

Ferreiro, E. (2001). Reflexões sobre alfabetização (24a ed.). São Paulo: Cortez.

Figueiredo, V. L. M. (2001). Adaptação brasileira do teste de Inteligência WISC-III. Tese de doutorado não-publicada, Universidade de Brasília, Brasília, DF.

Gombert, J. E. (1992). Metalinguistic development. Chicago: University of Chicago Press.

Gosche, B., Schwartz, A., \& Wells-Jensen, S. (2007). A cognitive approach to brailling errors. Journal of Visual Impairment and Blindness, 101, 416-428.

Günther, H. (1997). Aspects of a history of written language processing: Examples from the roman world and the early Middle Ages. In C. Pontecorvo (Ed.), Writing development: An interdisciplinary view (pp. 129-149). Amsterdam: John Benjamins. 
Laplane, A., \& Batista, C. (2008). Ver, não ver e aprender: A participação de crianças com baixa visão e cegueira na escola. Cadernos Cedes, 28, 209-228.

Lemle, M. (2003). Guia teórico do alfabetizador (15a ed.). São Paulo: Ática.

Mantoan, M. T. E. (2006). Inclusão escolar: O que é? Por quê? Como fazer? (2a ed., Coleção Cotidiano escolar: Ação docente). São Paulo: Moderna.

Ministério da Educação. (2006). Saberes e práticas da inclusão: Desenvolvendo competências para o atendimento às necessidades educacionais especiais de alunos cegos e de alunos com baixa visão (2a ed.). Brasília: MEC. Recuperado em 05 março 2008, de http:// portal.mec.gov.br/seesp/arquivos/pdf/alunoscegos.pdf

Morais, A. G. (2003). Ortografia: Ensinar e aprender (4a ed.). São Paulo: Ática.

Morais, A. G. (2006). Concepções e metodologias de alfabetização: Por que é preciso ir além da discussão sobre velhos métodos? Brasília, DF: Secretaria de Educação Básica. (Trabalho apresentado no Seminário Alfabetização e Letramento em Debate). Recuperado em 25 dezembro 2007, de http://portal.mec.gov.br/seb/ arquivos/pdf/Ensfund/alf_moarisconcpmetodalf.pdf

Nascimento, E., \& Flores-Mendoza, C. E. (2007). WISCIII e WAIS-III na avaliação da inteligência de cegos. Psicologia em Estudo, 12, 627-633.

Nicolaiewsky, C. A. (2008). Segmentação lexical na produção textual infantil em braille. Dissertação de mestrado não-publicada, Universidade Federal do Rio de Janeiro, Rio de Janeiro.

Nicolaiewsky, C. de A., \& Correa, J. (2008). Escrita ortográfica e revisão de texto em braille: Uma história de reconstrução de paradigmas sobre o aprender. Cadernos Cedes, 28, 229-244.

Pring, L. (1994). Touch and go: Learning to read Braille. Reading Research Quartely, 29, 67-74.

Rego, L. L. B. (2006). Alfabetização e letramento: Refletindo sobre as atuais controvérsias. Brasília, DF: Secretaria de Educação Básica. Recuperado em 25 dezembro 2007, de http://portal.mec.gov.br/seb/arquivos/pdf/Ensfund/ alfbsem.pdf

Sandbank, A. (2001). On the interplay of genre and writing conventions in early text writing. In L. Tolchinsky (Ed.), Developmental aspects in learning to write (pp. 55-75). The Netherlands: Kluwer Academic Publishers.

Soares, M. (2004). Letramento e alfabetização: As muitas facetas. Revista Brasileira de Educação, 25, 5-17.

Souza, E. C., \& Bandini, H. H. M. (2007). Programa de treinamento de consciência fonológica para crianças surdas bilíngues. Paideia (Ribeirão Preto), 17, 123-135.

Stein, L. (1994). Teste de desempenho escolar: Manual para aplicação e interpretação. São Paulo: Casa do Psicólogo.

Stone, J. (1995). Has Braille had its day? British Journal of Visual Impairment, 13, 80-81.
Tolchinsky, L. (2006). Writing and written numbers as source of knowledge. In E. Teubal, J. E. Dockrell, \& L. Tolchinsky (Eds.), Notational knowledge: Historical and developmental perspectives. Rotterdam: Sense Publishers.

Tolchinsky, L., \& Cintas, C. (2001). The development of graphic words in written Spanish: What can be learnt from counterexamples? In L. Tolchinsky (Ed.), Developmental aspects in learning to write (pp. 77-95). The Netherlands: Kluwer Academic Publishers.

Clarissa de Arruda Nicolaiewsky é Mestre em Psicologia pelo Programa de Pós-graduação em Psicologia do Instituto de Psicologia da Universidade Federal do Rio de Janeiro.

Jane Correa é Professora Associada do Instituto de Psicologia da Universidade Federal do Rio de Janeiro.

Recebido: $18 / 05 / 2008$

$1^{a}$ revisão: $30 / 04 / 2009$

Aceite final: 03/07/2009 